Article

\title{
Dynamic Spillovers between Gulf Cooperation Council's Stocks, VIX, Oil and Gold Volatility Indices
}

\author{
Abdullah Alqahtani ${ }^{1, *}$ and Julien Chevallier 2,3 \\ 1 Sawyer Business School, Suffolk University, Boston, 73 Tremont St, Boston, MA 02108, USA \\ 2 Department of Economics \& Management, IPAG Business School (IPAG Lab), 184 bd Saint-Germain, \\ 75006 Paris, France; julien.chevallier@ipag.fr \\ 3 Department of Economics \& Management, Université Paris 8 (LED), 2 rue de la Liberté, \\ 93526 Saint-Denis, France \\ * Correspondence: aa201512@suffolk.edu
}

Received: 3 March 2020; Accepted: 8 April 2020; Published: 11 April 2020

\begin{abstract}
This paper analyzes the conditional correlations between the stock market returns of countries that are members of the Gulf Cooperation Council (GCC). The innovative aspects of the paper consist of focusing on three volatility indices: the oil (OVX), gold (GVZ), and S\&P500 (VIX) markets (considered in log-difference). We use weekly data and resort to DCC-GARCH modeling. The novelty of the paper consists in revealing that: (i) GCC stock market returns are negatively correlated with each of the volatility measures, and the correlations are stronger during crisis periods; (ii) GCC stock returns are mostly correlated with oil shocks; and (iii) Saudi Arabia and Qatar are the most responsive to all shocks among the GCC countries, while Bahrain correlates weakly to shocks in oil, gold, and VIX. The most striking results feature extra sensitivity of Saudi Arabia and Qatar in terms of volatility indices, which should be the foremost concern of policymakers and banking analysts.
\end{abstract}

Keywords: Gulf Cooperation Council; DCC-GARCH; VIX; oil; gold

JEL Classification: C32; F30; F65

\section{Introduction}

The analysis of volatility spillover between commodity markets and financial markets has been a central focus of the financial literature for decades, mainly due to its crucial implications on risk management, asset pricing, and forecasting future volatility (Malik and Hammoudeh 2007). Numerous past studies have contributed to the literature of volatility spillover between commodity markets and financial markets in one way or another. The majority of the studies in this discipline have focused on the volatility spillover between crude oil and key financial markets (see, inter alia, Arouri et al. 2011; Guesmi and Fattoum 2014; Khalfaoui et al. 2015; Delcoure and Singh 2018; Hammoudeh et al. 2013; Kumar et al. 2012; Sadorsky 2012). A fundamental consensus from these studies is that oil price shocks have significant time-varying impacts on the relationship between oil markets and equity markets.

Within this body of the literature, few studies have paid attention to markets of gold or other precious metals. Using a VAR-GARCH model and daily data from 2000 to 2011, Mensi et al. (2013) showed that there are significant return and volatility transmissions between the S\&P 500 and commodity markets. In addition, the highest conditional correlations appear between the S\&P 500 and the gold index and between the S\&P 500 and WTI index. Moreover, using a DCC-GARCH model and daily data from January 2004 to May 2016, Maghyereh et al. (2017) found significant volatility spillover from crude oil to equity markets, and insignificant spillover from gold to equity markets in 
the Gulf Cooperation Council (GCC) region. By using various multivariate GARCH models, Pandey (2018) recently found that there are significant post-crisis volatility spillovers from both oil and gold markets on BRICS stock markets. Aziz (2018) has recently examined the impact of institutional quality on FDI inflows in the Arab region. From another interesting angle, Bley and Saad (2019) have tackled the analysis of technical trading rules in the Middle Eastern and North African areas.

This paper studies volatility indexes from a dynamic conditional correlation perspective in the GCC region. The main econometric methods consist of resorting to the Dynamic Conditional Correlation (DCC) model by Engle (2002). Alqahtani et al. (2020) have recently investigated co-integration and Granger causality between crude oil and the GCC stock markets. The impact of oil price uncertainty on the GCC stock markets has been analyzed as well by Alqahtani et al. (2019), in an ARMA-EGARCH framework looking at the co-movement between returns. Dkhili and Dhiab (2018) used a multivariate analysis based on panel unit root tests, cointegration, the Fully Modified Ordinary Least Squares (FMOLS), and the Dynamic Ordinary Least Squares (DOLS) to study the existence of a long-term integration within GCC countries. Finally, Alqahtani (2019) has tackled the topic of shocks transmission within the six GCC stock markets from a non-structural VAR econometrics approach.

Compared to the previous literature, our research's novelty in the domains of risk and financial management is to focus on volatility indices (considered in log-difference) for econometric development, instead of canonic returns. The main results feature new dynamics stemming from the volatility indexes of the GCC countries when studied in a conditional correlations framework. Based on empirical findings, one recommendation would be to induce policymakers to study the sensitivity of Saudi Arabia and Qatar to volatility in priority, among other GCC countries.

This study aims to complement the existing literature by analyzing the conditional correlations between the GCC stock markets and the volatility in the oil market, gold market, and equity market. Specifically, the conditional correlations between the weekly stock returns in the Gulf region and each of the three volatilities are examined using the DCC-GARCH model. This paper then considers three different volatility measures, namely the Crude Oil Volatility Index (OVX), the Gold Volatility Index (GVZ), and the S\&P 500 Volatility index (VIX). The oil volatility index is included due to the oil-dependent economies of the GCC region. Likewise, more significant shocks in crude oil markets are expected to impact the equity markets in the GCC. The GVZ index is included to capture shocks from the gold market. The equity volatility index VIX describes the uncertainty level of global equity markets, which are mainly based on the S\&P 500. The inclusion of the VIX is expected to isolate volatility clustering that is shared among all financial markets from the shocks from oil and gold markets.

The remainder of this paper is structured as follows. Section 2 explores background studies on the GCC countries. Section 3 elaborates on the specification of the DCC-GARCH model. Section 4 reports the data employed and empirical results from the DCC-GARCH models. Section 5 concludes and provides implications of the study.

\section{Literature Review}

Digging deeper into this vast literature, Arouri and Rault (2012) provide a panel analysis of the long-run links between oil prices and stock markets in GCC countries. Hammoudeh and Choi (2006) feature a vector-error correction (VEC) model for the short-run bilateral causal relationships among GCC weekly equity index returns. Mohanty et al. (2011) assess the relationship between changes in crude oil prices and equity returns in the GCC countries using country-level, as well as industry-level, stock return data. Zarour (2006) investigates the effect of the sharp increase in oil prices on stock market returns for five GCC countries using a vector autoregression (VAR) analysis. Maghyereh and Al-Kandari (2007) employ rank tests of nonlinear cointegration to examine the linkages between oil prices and the stock market in the GCC countries. Fayyad and Daly (2011) perform an empirical investigation into the relationship between oil price and stock market returns for seven countries (Kuwait, Oman, UAE, Bahrain, Qatar, UK, and the USA) by applying the VAR analysis. Akoum et al. (2012) introduce the wavelet coherency methodology in their empirical studies of stock market returns 
of the GCC countries, as well as two non-oil producing countries in the region (Egypt and Jordan). Nasreen et al. (2020) further examine the connectedness between the sukuk- and shariah-compliant stock indices in the GCC financial markets, based on wavelet analysis and Value-at-Risk (VaR).

While this paper is closely related to Malik and Hammoudeh (2007) and Maghyereh et al. (2017), who also studied conditional correlations in the context of the GCC region, there are some crucial differences between this study and the past evidence. First, this study considers the shocks in both the gold market and the international equity market—-the first of which is absent in Malik and Hammoudeh (2007), and the latter is lacking in Maghyereh et al. (2017). Second, this study adopts the DCC-GARCH framework over the simple BEKK-GARCH model used in Malik and Hammoudeh (2007) to model dynamic correlations. The findings of this study are expected to aid in decisions of hedging or portfolio diversification by equity market participants. Mensi et al. (2016) provide new evidence on hedges and safe havens for the Gulf stock markets using the wavelet-based quantile. In recent contributions, Loganathan et al. (2018) have employed the Threshold Error Correction (TECM) cointegration, and the nonlinear causality estimates to capture the nexus between real energy prices and financial stability for the GCC countries' tourism demand. Muharam et al. (2019) investigate in a GARCH( $p, q)$-DCC framework volatility spillovers from the world and the major regional markets to domestic stock markets that are conditional on the degree of integrations. Bilan et al. (2018) describe the impact of oil price on the Ruble-US dollar exchange rate. The analysis used an econometric model (VAR) built following the Engle-Granger methodology.

\section{Methodology}

This study applies Engle (2002) DCC-GARCH models for estimating the conditional correlations between GCC stock returns and each volatility measures. The DCC-GARCH model is by far the most widely adopted variant of the multivariate GARCH specification, mainly due to its parsimonious yet flexible nature ${ }^{1}$. Its main advantage lies in a two-step estimation procedure, as summarized by Engle (2009). ${ }^{2}$ Alternative multivariate GARCH models would feature the BEKK model from Baba et al. (1990), which is, however, notoriously difficult to estimate, given its scalar presentation and required computational power.

To begin, consider the following vector equation of stock returns and volatility:

$$
y_{t}=\mu_{t}+H_{t}^{1 / 2} \epsilon_{t}
$$

where $y_{t}$ is a $7 \times 1$ vector indexed by time containing the past values of the volatility index for each GCC country (and the shock), $\mu_{t}$ is a vector of conditional returns, and $\epsilon_{t}$ is a vector of standardized residuals. $H_{t}^{1 / 2}$ is the Cholesky factor of the dynamic conditional covariance matrix $H_{t}$ which is defined as

$$
H_{t}=D_{t} R_{t} D_{t}
$$

where $R_{t}=\left(\operatorname{diag}\left(Q_{t}\right)\right)^{-1 / 2} Q_{t}\left(\operatorname{diag}\left(Q_{t}\right)\right)^{-1 / 2}$ is a $7 \times 7$ dynamic conditional correlation matrix, and $D_{t}=$ $\operatorname{diag}\left(h_{11, t^{\prime}}^{\frac{1}{2}} h_{22, t^{\prime}}^{\frac{1}{2}} \ldots, h_{77, t}^{\frac{1}{2}}\right)$ is a diagonal matrix of conditional standard deviations, in which $h_{i i, t}=$ $c_{i}+\alpha_{i} u_{i i, t-1}^{2}+\beta_{i} h_{i, t-1-1}$. The conditional covariance matrix of standardized residuals $u_{t}=h_{t}^{1 / 2} \epsilon_{t}$ is specified as:

$$
Q_{t}=(1-a-b) \bar{Q}+a\left(\widetilde{u}_{t-1} \vec{u}_{t-1}\right)+b Q_{t-1}
$$

1 See, inter alia, Guesmi and Fattoum (2014) and Maghyereh et al. (2017) for the sampled application of DCC-GARCH in similar studies.

2 The problem of multivariate conditional variance estimation can be simplified by estimating univariate GARCH models for each asset, and then using transformed residuals resulting from the first stage, estimating a conditional correlation estimator. 
where $\bar{Q}$ is the weighted average of the unconditional covariance of the standardized residuals, $\widetilde{u}_{t-1} \vec{u}_{t-1}$ is a lagged function of the standardized residuals, and $Q_{t-1}$ is the past realization of the conditional covariance. Given that $a+b<1$, process (3) ensures $H_{t}$ is positive definite. In most applied specifications of DCC, only the first lagged realization of the standardized residuals and the conditional covariance are considered. ${ }^{3}$ Finally, the conditional correlation can be written as

$$
\begin{gathered}
R_{t}=\left\{\rho_{i j, t}\right\} \\
\rho_{i j, t}=\frac{q_{i j, t}}{\sqrt{q_{i i, t}} \sqrt{q_{j j, t}}}
\end{gathered}
$$

where $q_{i j, t}$ are the elements of $i$-th and $j$-th market in $Q_{t}$. The unknown parameters $a$ and $b$ are estimated using the quasi-maximum likelihood method as introduced in Bollerslev and Wooldridge (1992). ${ }^{4}$

\section{Data and Empirical Results}

\subsection{Data}

The timeframe runs from 9 July 2004 to 7 September 2018 in weekly frequency. ${ }^{5}$ We opted to use weekly data and chose Tuesday as the weekday for all the variables, as GCC markets are off on Friday and Saturday (it used to be Thursday and Saturday for some markets until three years ago). This is a common practice in papers about the GCC to choose from mid -week. Also, we did not select the last day of the week, like Thursday or Friday, to avoid market sensitivity to end-of-week trading.

This study employs weekly observations of stock market returns from the six GCC countries and three volatility indices (considered in log-difference). The stock returns are represented by weekly stock market indices for Bahrain (Bourse All-Share Index), Kuwait (KSE Index), Oman (Muscat SE Index), Qatar (QE General Index), Saudi Arabia (Tadawul All-Share Index), and UAE (Abu Dhabi General Index). Some unit root tests (ADF and KPSS) are proposed in the Appendix A: they point towards the presence of a unit root in the raw data, which can be avoided by log-differencing the series. The three volatility indices, namely the OVX, the GVZ, and the VIX, consist of different observation lengths due to data availability, spanning from 14 May 2007, 3 June 2008, and 4 July 2004 to 15 August 2018, respectively. The OVX data has 532 observations, the GVZ data has 482 observations, and the VIX data has 668 observations. All data are obtained from the Bloomberg database (see the Appendix A for a full list of the data source) and are expressed in first-differenced natural logs.

Table 1 presents the descriptive statistics of each volatility index and the GCC stock returns. The mean data for oil (OVX) is 0.0013 , and for gold (GVZ) and the equity market (VIX) it is 0.1130 and -0.0115 , respectively. According to this data, for the majority of observations used in estimations, the oil price is increasing, and the gold price and equity index decreasing. Contrarily, the standard deviations show that OVX was less volatile (9.4319), as compared to GVZ (11.100) and VIX (13.646). All volatility indices are slightly right-skewed, while the GCC weekly stock returns are slightly left-skewed. Many series are characterized by a significant first-order autocorrelation, as shown by the Ljung-Box statistic. Thus, it is possible to fit an ARMA representation for the conditional mean equations. Moreover, Table 2 tabulates the unconditional correlation matrices of each model. The unconditional correlations between the GCC stock returns and each of the volatility indices are always negative, but with different magnitudes. In contrast, the cross-border correlations within GCC stock markets are still positive.

3 The interested reader can fin in the Appendix A Table related to "VAR Lag Selection criteria (up to ten lags)", which points to lag 1 for two criteria (BIC and Hannan-Quinn), whereas the AIC indicates lag 2.

4 Newest estimation developments regarding Bayesian methods applied to GARCH models can be found in Ausín and Galeano (2007), Ardia (2008).

5 This was the largest we could gather in terms of availability at the time of writing the paper. 
Table 1. Descriptive statistics.

\begin{tabular}{|c|c|c|c|c|c|c|}
\hline \multicolumn{7}{|c|}{ (A) Crude Oil Volatility Index-Gulf Cooperation Council (OVX-GCC) Countries } \\
\hline & Mean & SD & Skewness & Kurtosis & Ljung-Box & Jarque-Bera \\
\hline OVX & 0.001 & 9.431 & 0.902 & 7.272 & $13.031^{* * *}$ & $477.001^{* * *}$ \\
\hline Saudi Arabia & 0.006 & 3.334 & -1.050 & 8.784 & $0.143^{* * *}$ & $839.470 * * *$ \\
\hline Kuwait & -0.083 & 2.121 & -1.818 & 12.734 & $32.699 * * *$ & $2393.800^{* * *}$ \\
\hline UAE & 0.071 & 2.986 & -1.957 & 16.753 & $7.020 * * *$ & $4532.600^{* * *}$ \\
\hline Qatar & 0.053 & 3.625 & -1.654 & 14.745 & $1.312^{* * *}$ & $3300.600 * * *$ \\
\hline Bahrain & -0.091 & 1.492 & -1.118 & 9.592 & $9.316^{* * *}$ & $1074.300^{* * *}$ \\
\hline Oman & -0.057 & 2.894 & -2.049 & 22.917 & $9.686^{* * *}$ & $9166.100^{* * *}$ \\
\hline \multicolumn{7}{|c|}{ (B) Gold Volatility Index-GCC (GVZ-GCC) Countries } \\
\hline & Mean & SD & Skewness & Kurtosis & Ljung-Box & Jarque-Bera \\
\hline GVZ & -0.113 & 11.100 & 0.671 & 5.422 & $33.292 * * *$ & $154.140 * * *$ \\
\hline Saudi Arabia & -0.042 & 3.180 & -0.864 & 7.180 & $0.0233 * * *$ & $411.110^{* * *}$ \\
\hline Kuwait & -0.156 & 2.170 & -1.791 & 12.50 & $30.256^{* * *}$ & $2073.300 * * *$ \\
\hline UAE & -0.010 & 2.993 & -2.211 & 17.358 & $9.427 * * *$ & $4533.200 * * *$ \\
\hline Qatar & -0.047 & 3.621 & -1.812 & 15.718 & $2.605^{* * *}$ & $3512.700 * * *$ \\
\hline Bahrain & -0.159 & 1.489 & -1.204 & 10.107 & $6.327^{* * *}$ & $1131.100^{* * *}$ \\
\hline Oman & -0.207 & 2.923 & -2.123 & 23.704 & $16.795^{* * *}$ & $8971.300^{* * *}$ \\
\hline \multicolumn{7}{|c|}{ (C) S\&P 500 Volatility Index-GCC (VIX-GCC) Countries } \\
\hline & Mean & SD & Skewness & Kurtosis & Ljung-Box & Jarque-Bera \\
\hline VIX & -0.011 & 13.646 & 0.581 & 6.341 & $32.733^{* * *}$ & $348.520 * * *$ \\
\hline Saudi Arabia & 0.043 & 3.775 & -1.412 & 9.538 & $7.097^{* * *}$ & $1412.100^{* * *}$ \\
\hline Kuwait & 0.038 & 2.151 & -1.514 & 10.869 & $43.561^{* * *}$ & $1979 * * *$ \\
\hline UAE & 0.124 & 3.213 & -1.201 & 12.398 & $0.022^{* * *}$ & $2619.200^{* * *}$ \\
\hline Qatar & 0.100 & 3.782 & -1.075 & 11.472 & $0.022 * * *$ & $2126.700 * * *$ \\
\hline Bahrain & -0.018 & 1.565 & -0.456 & 8.789 & $11.775^{* * *}$ & $956.180^{* * *}$ \\
\hline Oman & 0.036 & 2.765 & -1.840 & 22.510 & $4.767^{* * *}$ & $10,972 * * *$ \\
\hline
\end{tabular}

Note: ${ }^{*}$ denotes null rejection at $10 \% .{ }^{* *}$ denotes null rejection at $5 \% .{ }^{* * *}$ denotes null rejection at $1 \%$.

Table 2. Unconditional correlations.

\begin{tabular}{|c|c|c|c|c|c|c|c|}
\hline \multicolumn{8}{|c|}{ (A) OVX-GCC Countries } \\
\hline & OVX & Saudi Arabia & Kuwait & UAE & Qatar & Bahrain & Oman \\
\hline OVX & 1 & & & & & & \\
\hline Saudi Arabia & -0.242 & 1 & & & & & \\
\hline Kuwait & -0.170 & 0.426 & 1 & & & & \\
\hline UAE & -0.203 & 0.477 & 0.419 & 1 & & & \\
\hline Qatar & -0.173 & 0.535 & 0.496 & 0.502 & 1 & & \\
\hline Bahrain & -0.022 & 0.323 & 0.523 & 0.466 & 0.364 & 1 & \\
\hline Oman & -0.125 & 0.534 & 0.494 & 0.646 & 0.590 & 0.510 & 1 \\
\hline \multicolumn{8}{|c|}{ (B) GVZ-GCC Countries } \\
\hline & GVZ & Saudi Arabia & Kuwait & UAE & Qatar & Bahrain & Oman \\
\hline GVZ & 1 & & & & & & \\
\hline Saudi Arabia & -0.198 & 1 & & & & & \\
\hline Kuwait & -0.081 & 0.467 & 1 & & & & \\
\hline UAE & -0.078 & 0.490 & 0.424 & 1 & & & \\
\hline Qatar & -0.117 & 0.546 & 0.506 & 0.505 & 1 & & \\
\hline Bahrain & 0.026 & 0.347 & 0.544 & 0.483 & 0.366 & 1 & \\
\hline Oman & -0.041 & 0.555 & 0.505 & 0.647 & 0.590 & 0.515 & 1 \\
\hline
\end{tabular}


Table 2. Cont.

\begin{tabular}{cccccccc}
\hline \multicolumn{7}{c}{ (C) VIX-GCC Countries } \\
\hline & VIX & Saudi Arabia & Kuwait & UAE & Qatar & Bahrain & Oman \\
\hline VIX & 1 & & & & & & \\
Saudi Arabia & -0.215 & 1 & & & & & \\
Kuwait & -0.109 & 0.408 & 0.431 & 1 & & & \\
UAE & -0.131 & 0.451 & 0.423 & 0.444 & 1 & & 1 \\
Qatar & -0.223 & 0.398 & 0.482 & 0.398 & 0.334 & 1 & \\
Bahrain & -0.029 & 0.267 & 0.460 & 0.563 & 0.501 & 0.463 & \\
Oman & -0.149 & 0.438 & & & & & \\
\hline
\end{tabular}

\subsection{Empirical Results}

The regressions include the six exchanges and each of the volatility indices, consecutively. Table 3 shows the estimated DCC-GARCH models with different volatility measures employed in each model. The table is divided into three panels for each DCC-GARCH model.

Table 3. DCC-GARCH Estimation.

\begin{tabular}{|c|c|c|c|c|c|c|}
\hline \multirow{3}{*}{ Shock from: } & \multicolumn{2}{|c|}{ Model I } & \multicolumn{2}{|c|}{ Model II } & \multicolumn{2}{|c|}{ Model III } \\
\hline & \multicolumn{2}{|c|}{ OVX } & \multicolumn{2}{|c|}{ GVZ } & \multicolumn{2}{|c|}{ VIX } \\
\hline & Coefficient & $p$-Value & Coefficient & $p$-Value & Coefficient & $p$-Value \\
\hline \multicolumn{7}{|c|}{ Panel A: estimates of $\alpha$} \\
\hline Shock & 0.062 & 0.303 & 0.004 & 0.371 & $0.016^{* * *}$ & 0.008 \\
\hline Saudi Arabia & $0.265^{* * *}$ & 0.001 & $0.252^{* *}$ & 0.016 & $0.312^{* * *}$ & 0.000 \\
\hline Kuwait & $0.451^{* * *}$ & 0.001 & $0.451^{* *}$ & 0.017 & $0.470^{* * *}$ & 0.001 \\
\hline UAE & $0.118^{* *}$ & 0.020 & $0.133^{* *}$ & 0.017 & $0.164^{* * *}$ & 0.002 \\
\hline Qatar & $0.127^{* * *}$ & 0.001 & $0.127 * * *$ & 0.000 & $0.157^{* * *}$ & 0.006 \\
\hline Bahrain & 0.118 & 0.298 & $0.143^{* *}$ & 0.080 & $0.155 *$ & 0.064 \\
\hline Oman & $0.202^{* * *}$ & 0.001 & $0.189^{* * *}$ & 0.005 & $0.224 * * *$ & 0.001 \\
\hline \multicolumn{7}{|c|}{ Panel B: estimates of $\beta$} \\
\hline Shock & $0.826^{* * *}$ & 0.001 & $0.994^{* * *}$ & 0.001 & $0.982 * * *$ & 0.001 \\
\hline Saudi Arabia & $0.691^{* * *}$ & 0.001 & $0.706^{* * *}$ & 0.001 & $0.686^{* * *}$ & 0.001 \\
\hline Kuwait & $0.465^{* * *}$ & 0.001 & $0.418^{* * *}$ & 0.007 & $0.456^{* * *}$ & 0.001 \\
\hline UAE & $0.836^{* * *}$ & 0.001 & $0.825^{* * *}$ & 0.001 & $0.806^{* * *}$ & 0.001 \\
\hline Qatar & $0.866^{* * *}$ & 0.001 & $0.864^{* * *}$ & 0.001 & $0.841^{* * *}$ & 0.001 \\
\hline Bahrain & $0.777^{* * *}$ & 0.002 & $0.774^{* * *}$ & 0.001 & $0.759^{* * *}$ & 0.001 \\
\hline Oman & $0.748^{* * *}$ & 0.001 & $0.742^{* * *}$ & 0.001 & $0.725^{* * *}$ & 0.001 \\
\hline \multicolumn{7}{|l|}{ Panel C: } \\
\hline . & $0.010^{* *}$ & 0.012 & $0.014^{* *}$ & 0.040 & $0.009^{* * *}$ & 0.001 \\
\hline$b$ & $0.945^{* * *}$ & 0.001 & $0.887^{* * *}$ & 0.001 & $0.964^{* * *}$ & 0.001 \\
\hline
\end{tabular}

Note: This Table presents DCC estimates. The order of ARMA $(1,1)$ is used for the conditional mean equations, and the order of $\operatorname{GARCH}(1,1)$ is used for the conditional variance equations. * denotes null rejection at $10 \%$.

** denotes null rejection at $5 \%$. ${ }^{* * *}$ denotes null rejection at $1 \%$.

Panel A reports the estimated ARCH parameter $\alpha$, which measures the response of the conditional volatility to external shocks. Panel A reveals that almost all estimates of $\alpha$ are statistically significant, except for Bahrain's stock return in Model I, as well as the volatility from oil (Model I) and gold markets (Model II). In terms of magnitudes, all estimated $\alpha$ are above 0.1 , which implies that the volatility of GCC stock returns is responsive to market events, in particular, the shocks from equity markets.

Turning to Panel B, the estimated GARCH parameter $\beta$ s are statistically significant and positive in all cases. The magnitudes of the $\beta \mathrm{s}$ in all cases are close to 0.9 , except for the case of Kuwait in all models. This suggests that the conditional volatility in Kuwait's stock market takes a relatively short time to diminish from past shocks compared to its neighboring GCC countries. Furthermore, 
all estimated models have satisfied the mean-reverting condition, where $0<\alpha_{i j}+\beta_{i j}<1$. The results of the estimated $\alpha$ and $\beta$ coefficients indicate the presence of conditional volatility in the data.

Given the conditional variance equations, Figure $1 \mathrm{~A}-\mathrm{C}$ below depicts the dynamic conditional correlations of each model. The historical values of the OVX, GVZ, and VIX indices are illustrated in Figure $2 \mathrm{~A}-\mathrm{C}$, respectively, for a better comparison.

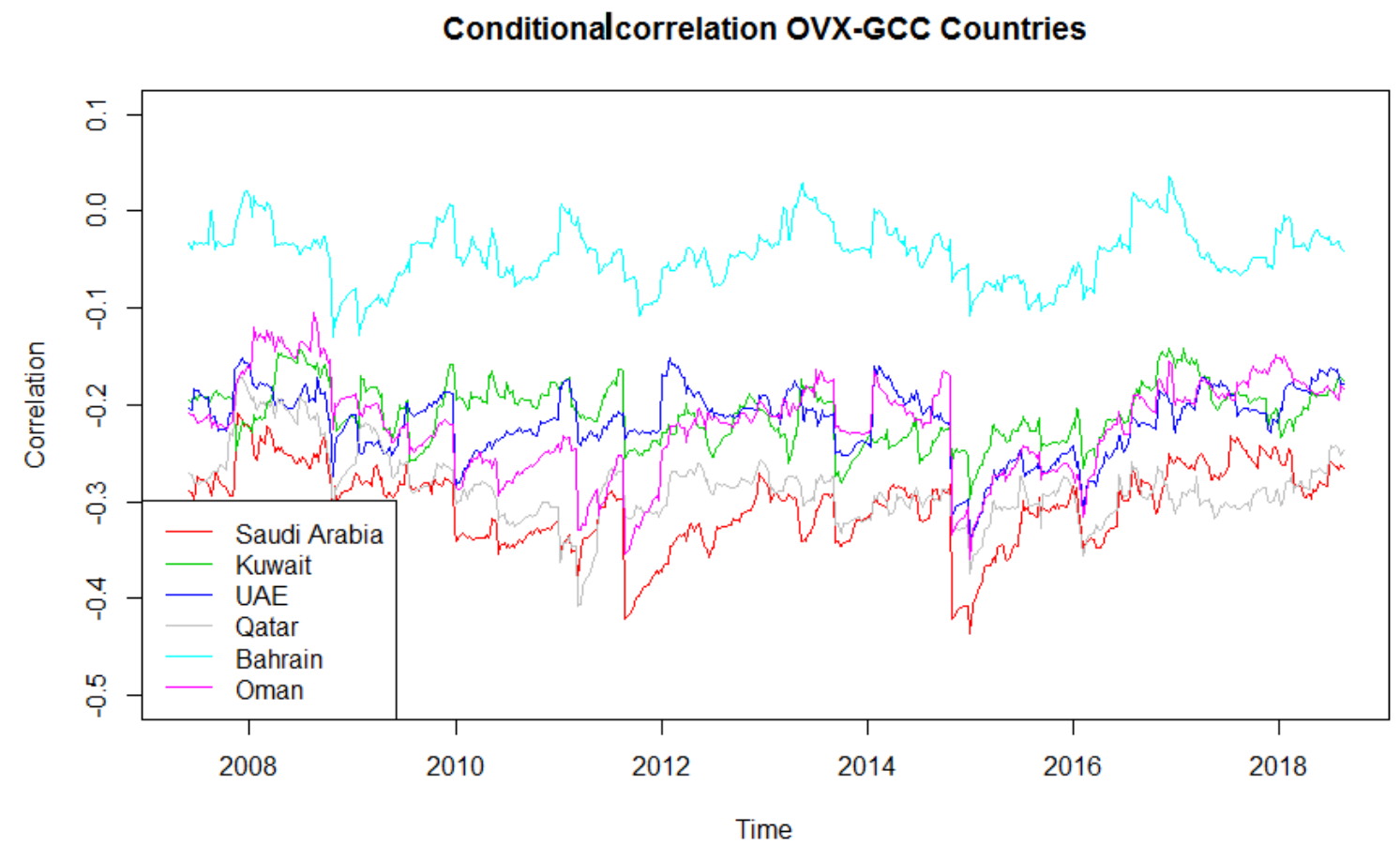

(A)

Conditional correlation GzV-GCC Countries

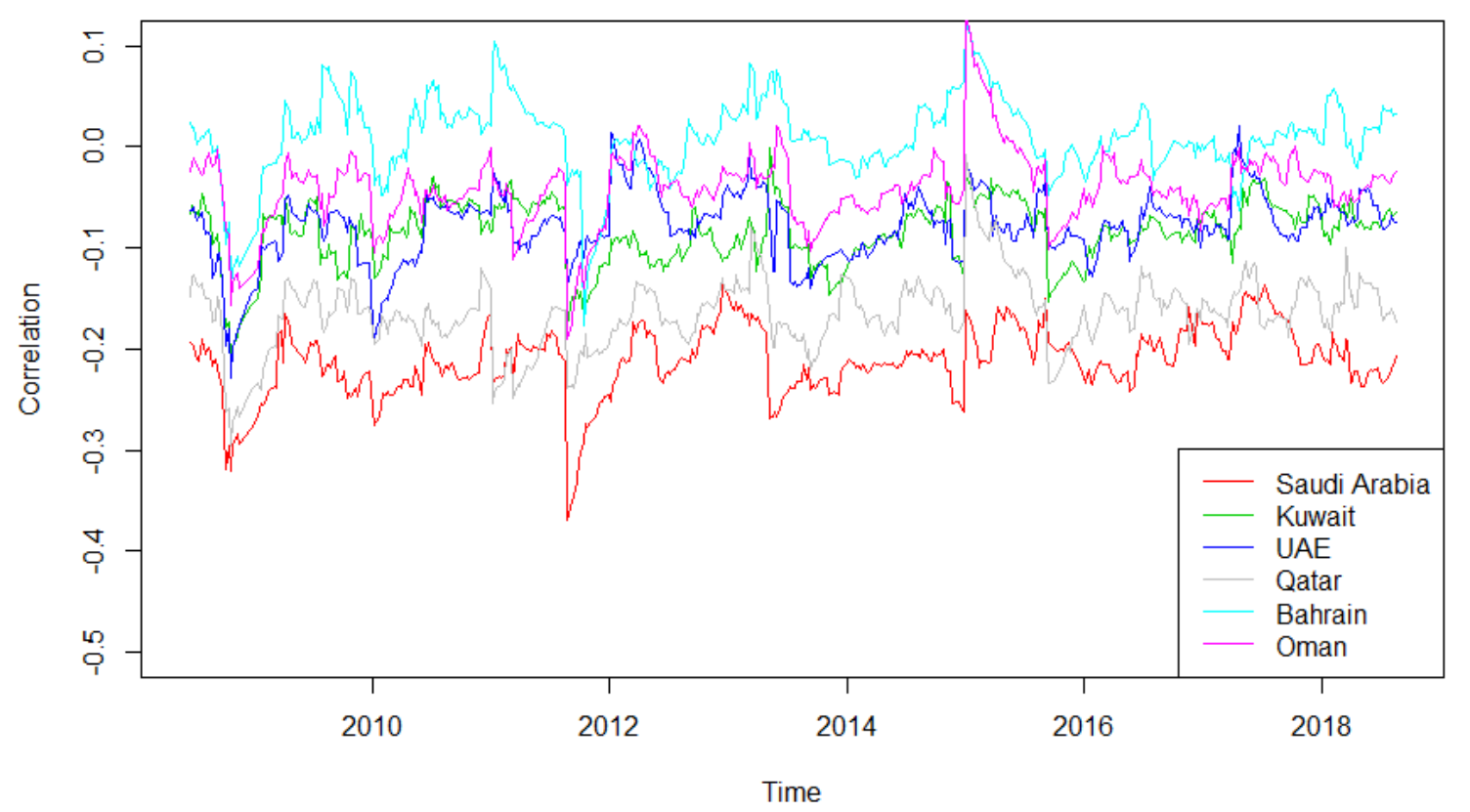

(B)

Figure 1. Cont. 


\section{Conditional correlation VIX-GCC Countries}

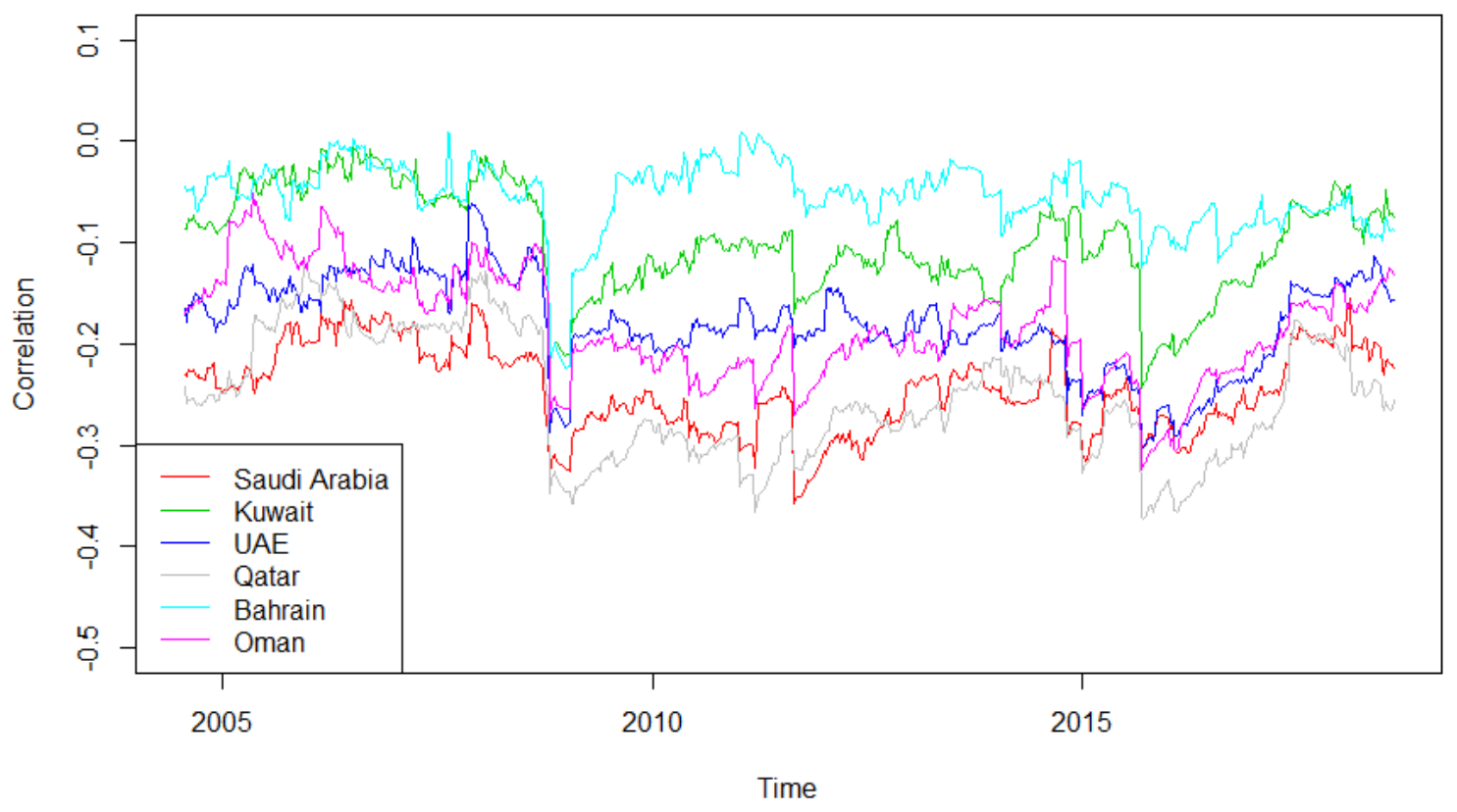

(C)

Figure 1. (A) Conditional Correlations for OVX-GCC Countries. Note: This Figure presents conditional correlations for the OVX-GCC countries. (B) Conditional Correlation: GVZ-GCC Countries. Note: This Figure presents conditional correlations for GZV-GCC countries. (C) Conditional Correlation: VIX-GCC Countries. Note: This Figure presents conditional correlations for VIX-GCC countries.

\section{OVX index}

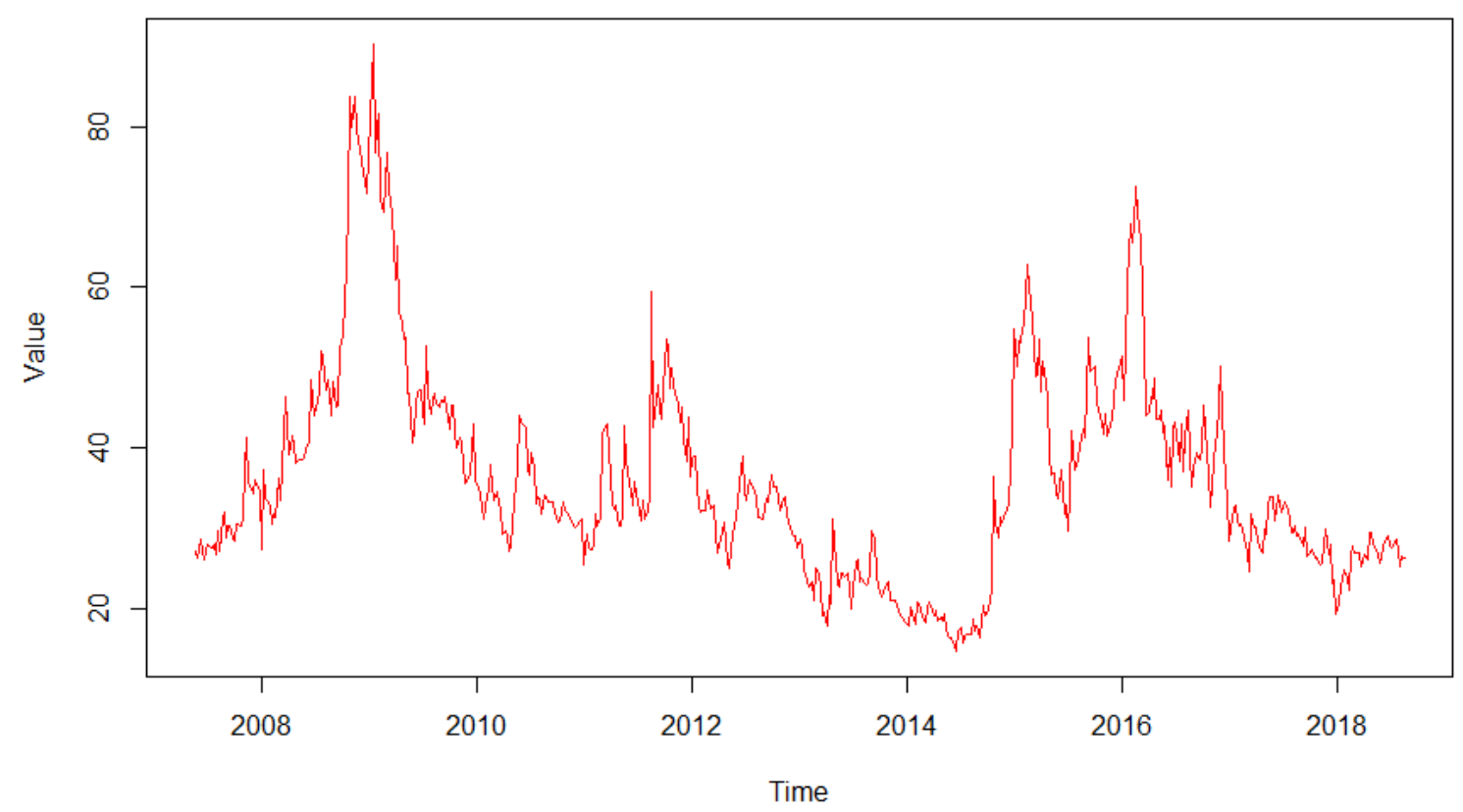

(A)

Figure 2. Cont. 


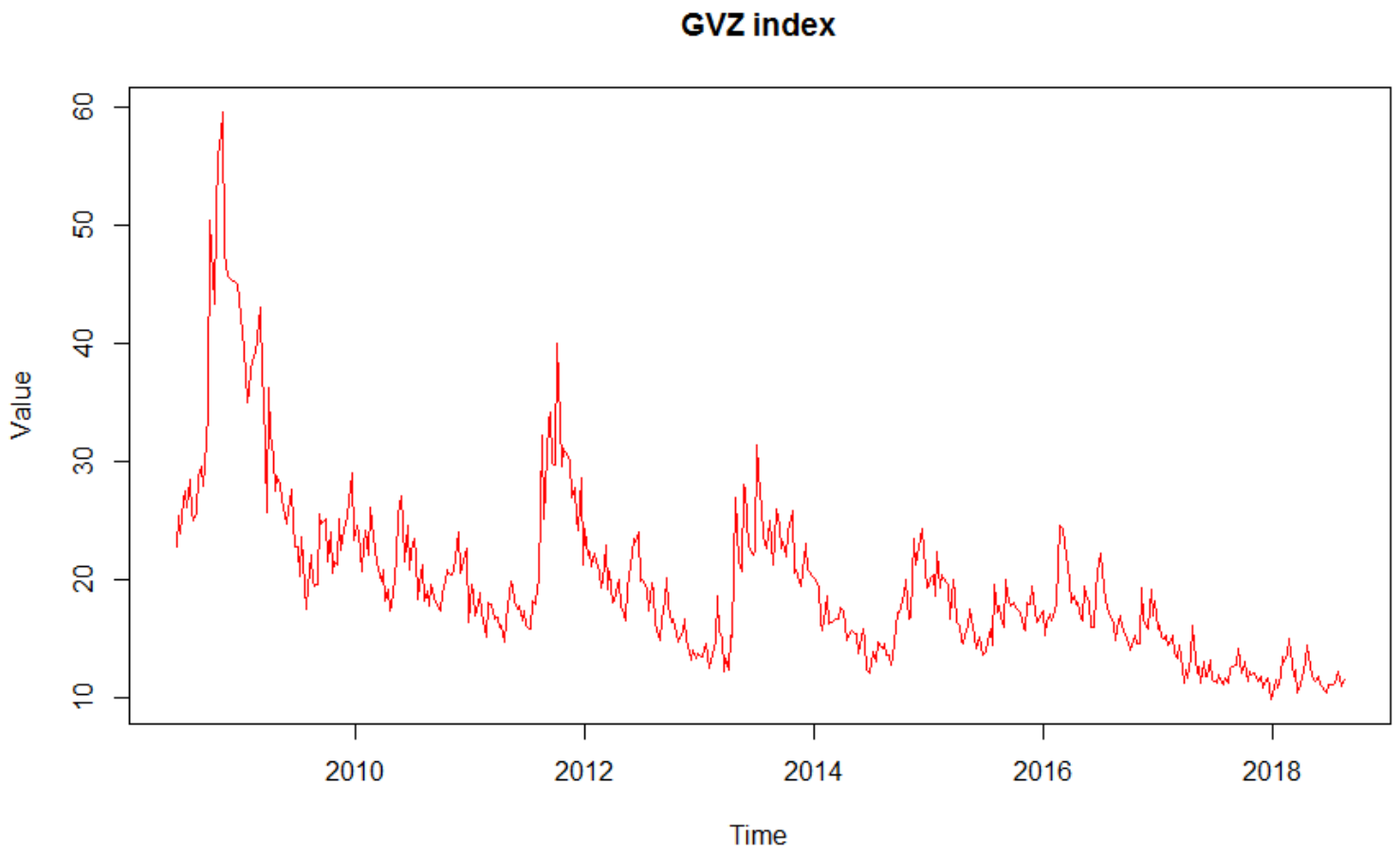

(B)

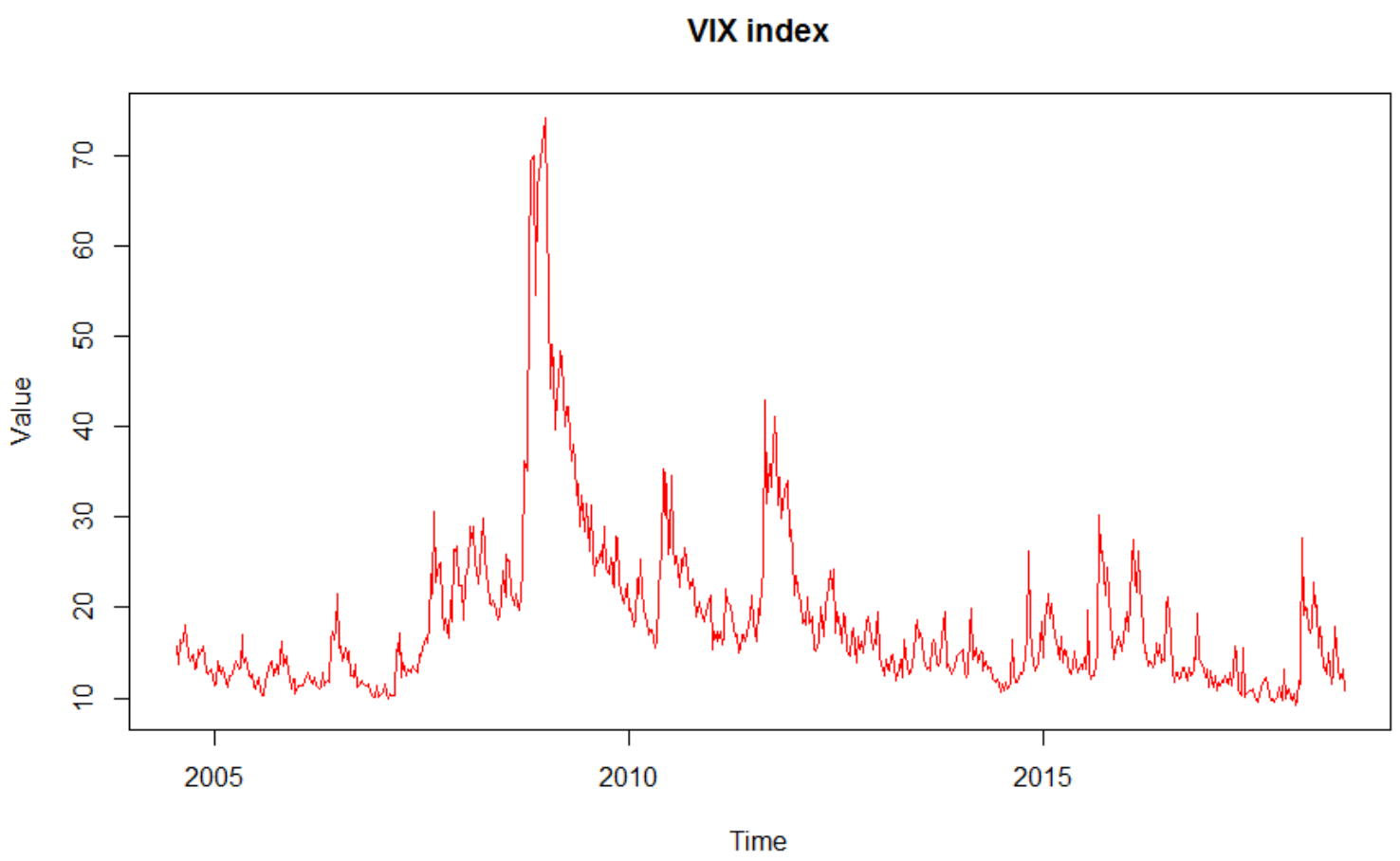

(C)

Figure 2. (A) OVX index, 14 May 2007-15 August 2018. Note: This Figure presents the index OVX. (B) GVZ index, 3 June 2008-15 August 2018. Note: This Figure presents the index GVZ. (C) VIX index, 4 July 2004-15 August 2018. Note: This Figure presents the index VIX.

The conditional correlations displayed in Figure 1A, $\mathrm{C}$ are the output of the DCC $\mathrm{H}_{\mathrm{t}}$ matrix, and they are naturally scaled between -1 and +1 . Figure $1 \mathrm{~A}$ portrays the dynamic conditional correlations between each GCC stock market and oil markets. It appears that the conditional correlations are 
negative from 2008 to 2018, indicating that higher volatility in oil markets induces lower stock returns in GCC. The highest conditional correlations are observed in Saudi Arabia and followed by Qatar, while the stock market in Bahrain is least-correlated with the oil market among its peers. Moreover, referring to both Figures $1 \mathrm{~A}$ and 2A, the co-movements between oil volatility and GCC stock returns tend to be most active during turmoil periods. The correlations between oil and the GCC stock markets increased during the periods of 2008-2009 (Global Financial crisis), mid-2011 (European Sovereign debt crisis), and 2014-2015 (oil price plummeting). For OVX-GCC countries, the average DCC coefficient is almost positive for Bahrain, whereas it evolves in negative territory for the other countries. For GZV-GCC countries, the average DCC coefficient is again mostly positive for Bahrain, whereas it evolves between -0.1 and -0.3 for other countries. For VIX-GCC countries, the difference is striking. Indeed, the average DCC coefficient of Bahrain becomes negative as well, oscillating until -0.2. The lowest DCC coefficient is recorded for Qatar below -0.3 . This finding of negative correlations between oil shocks and stock returns is consistent with ex-ante expectations, and the general conclusions from the literature (see, for instance, Guesmi and Fattoum 2014; Delcoure and Singh 2018; Hammoudeh et al. 2013; Maghyereh et al. 2017).

Figure 1B illustrates the conditional correlations between the gold market and the GCC stock markets. Similar to the oil-equity link, the conditional correlations of the gold-equity link are mostly negative, but with relatively lower magnitudes than the correlations between the oil and the GCC stock markets. This result is consistent with the earlier finding of Maghyereh et al. (2017), who found that the GCC stock markets are more dependent on oil markets than the gold market. The strongest correlation appears again between the stock market of Saudi Arabia and the gold market, and is followed by Qatar. The weakest correlation is found in Bahrain, where the conditional correlation coefficient is revolving around zero over the sample period. Figure 2B shows the historical trend of the GVZ, which shares a similar pattern with the OVX, except that the volatility is milder during the post-2014 period, as the price of gold is less affected by oil price fluctuations. Generally, the negative correlations between gold and the GCC stock markets are intensified during the periods of 2008-2009 and mid-2011. Interestingly, one may notice that the correlations between the gold and GCC stock markets, especially Bahrain, Oman, and Qatar, turned positive in early-2015.

Lastly, Figures $1 \mathrm{C}$ and 2C postulate the dynamic correlation between the VIX and GCC stock returns, as well as the historical values of the VIX index. The conditional correlations between each GCC stock market and the VIX index are generally negative, even within a more extended observation period (2005 to 2018). Interestingly, Figure 1C shows that the Bahrain stock market tends to behave independently to the shocks of international equity markets. The conditional correlation of VIX-Bahrain fluctuates mostly within 0.00 to -0.10 , except for the negative correlations during the 2008 global financial crisis. Saudi Arabia and Qatar exert, again, the strongest correlations with the volatility measure as compared to the other GCC stock markets.

\subsection{Diagnostic Checks}

To gauge the validity of the parameters estimated in Table 3, we run several diagnostic tests. They are applied to the six GCC countries series only, for the sake of brevity. ${ }^{6}$

In Panel A of Table 4, we reproduce Ljung-Box Q Statistics in the standardized residuals of the GARCH (estimated model during step \#1 of the DCC) for each of the six GCC countries. It can be observed that we accept the null hypothesis of no autocorrelation in the standardized residuals, based on this portmanteau test statistic.

6 Unformatted diagnostic tests for other series can be sent upon reasonable request. 
Table 4. Diagnostic Tests.

\begin{tabular}{|c|c|c|c|c|c|}
\hline \multicolumn{6}{|c|}{ Panel A: Ljung-Box Q Statistics in the Standardized Residuals of the GARCH (Estimated Model during Step \#1 of the DCC) } \\
\hline \multicolumn{6}{|l|}{ Saudi Arabia } \\
\hline Lag & $\mathrm{ACF}$ & & & \multicolumn{2}{|c|}{ Q [p. crit.] } \\
\hline-0.030 & -0.028 & & & \multicolumn{2}{|c|}{$[0.208]$} \\
\hline \multicolumn{6}{|l|}{ Kuwait } \\
\hline Lag & $\mathrm{ACF}$ & & & \multicolumn{2}{|c|}{ Q [p. crit.] } \\
\hline 0.002 & 0.009 & & & \multicolumn{2}{|c|}{ [0.187] } \\
\hline \multicolumn{6}{|l|}{ UAE } \\
\hline Lag & $\mathrm{ACF}$ & & & \multicolumn{2}{|c|}{ Q [p. crit.] } \\
\hline 0.051 & 0.054 & & & \multicolumn{2}{|c|}{ [0.175] } \\
\hline \multicolumn{6}{|l|}{ Qatar } \\
\hline Lag & $\mathrm{ACF}$ & & & \multicolumn{2}{|c|}{ Q [p. crit.] } \\
\hline 0.014 & 0.006 & & & \multicolumn{2}{|c|}{ [0.149] } \\
\hline \multicolumn{6}{|l|}{ Bahrain } \\
\hline Lag & $\mathrm{ACF}$ & & & \multicolumn{2}{|c|}{ Q [p. crit.] } \\
\hline 0.040 & 0.040 & & & \multicolumn{2}{|c|}{ [0.273] } \\
\hline \multicolumn{6}{|l|}{ Oman } \\
\hline Lag & $\mathrm{ACF}$ & & & \multicolumn{2}{|c|}{ Q [p. crit.] } \\
\hline-0.002 & -0.004 & & & \multicolumn{2}{|c|}{ [0.547] } \\
\hline \multicolumn{6}{|c|}{ Panel B: Engle and Sheppard (2001) Test of CCC versus DCC (Estimated Model during Step \#2 of the DCC) } \\
\hline Bahrain \& GVZ & H0: Lambda $=0$ & Bahrain \& OVX & H0: Lambda $=0$ & Bahrain \& VIX & H0: Lambda $=0$ \\
\hline CCC log-likelihood: & 8652 & CCC log-likelihood: & 5543 & CCC log-likelihood: & 5856 \\
\hline DCC log-likelihood: & 8550 & DCC log-likelihood: & 5525 & DCC log-likelihood: & 5754 \\
\hline Chi2 value: & 204 & Chi2 value: & 36 & Chi2 value: & 204 \\
\hline$p$-value & 0.001 & $p$-value & 0.001 & $p$-value & 0.001 \\
\hline
\end{tabular}


Table 4. Cont.

\begin{tabular}{|c|c|c|c|c|c|}
\hline Kuwait \& GVZ & H0: Lambda $=0$ & Kuwait \& OVX & H0: Lambda $=0$ & Kuwait \& VIX & H0: Lambda $=0$ \\
\hline CCC log-likelihood: & 5732 & CCC log-likelihood: & 5470 & CCC log-likelihood: & 5554 \\
\hline DCC log-likelihood: & 5609 & DCC log-likelihood: & 5122 & DCC log-likelihood: & 5463 \\
\hline Chi2 value: & 246 & Chi2 value: & 696 & Chi2 value: & 182 \\
\hline$p$-value & 0.001 & $p$-value & 0.001 & $p$-value & 0.001 \\
\hline UAE \& GVZ & H0: Lambda $=0$ & UAE \& OVX & H0: Lambda $=0$ & UAE \& VIX & H0: Lambda $=0$ \\
\hline CCC log-likelihood: & 9843 & CCC log-likelihood: & 5170 & CCC log-likelihood: & 5855 \\
\hline DCC log-likelihood: & 9737 & DCC log-likelihood: & 5122 & DCC log-likelihood: & 5546 \\
\hline Chi2 value: & 212 & Chi2 value: & 96 & Chi2 value: & 618 \\
\hline$p$-value & 0.001 & $p$-value & 0.001 & $p$-value & 0.001 \\
\hline Oman \& GVZ & H0: Lambda $=0$ & Oman \& OVX & H0: Lambda $=0$ & Oman \& VIX & H0: Lambda $=0$ \\
\hline CCC log-likelihood: & 9284 & CCC log-likelihood: & 7071 & CCC log-likelihood: & 7976 \\
\hline DCC log-likelihood: & 8427 & DCC log-likelihood: & 6707 & DCC log-likelihood: & 7609 \\
\hline Chi2 value: & 1714 & Chi2 value: & 728 & Chi2 value: & 734 \\
\hline$p$-value & 0.001 & $p$-value & 0.001 & $p$-value & 0.001 \\
\hline Qatar \& GVZ & H0: Lambda $=0$ & Qatar \& OVX & H0: Lambda $=0$ & Qatar \& VIX & H0: Lambda $=0$ \\
\hline CCC log-likelihood: & 10,825 & CCC log-likelihood: & 17,334 & CCC log-likelihood: & 1479 \\
\hline DCC log-likelihood: & 10,607 & DCC log-likelihood: & 16,913 & DCC log-likelihood: & 1066 \\
\hline Chi2 value: & 436 & Chi2 value: & 842 & Chi2 value: & 826 \\
\hline$p$-value & 0.001 & $p$-value & 0.001 & $p$-value & 0.001 \\
\hline Saudi Arabia \& GVZ & H0: Lambda $=0$ & Saudi Arabia \& OVX & H0: Lambda $=0$ & Saudi Arabia \& VIX & H0: Lambda $=0$ \\
\hline CCC log-likelihood: & 9048 & CCC log-likelihood: & 6373 & CCC log-likelihood: & 2647 \\
\hline DCC log-likelihood: & 8880 & DCC log-likelihood: & 6188 & DCC log-likelihood: & 2287 \\
\hline Chi2 value: & 336 & Chi2 value: & 370 & Chi2 value: & 720 \\
\hline$p$-value & 0.001 & $p$-value & 0.001 & $p$-value & 0.001 \\
\hline
\end{tabular}

Note: PACF stands for Partial Autocorrelation Function. ACF stands for Autocorrelation Function. P. crit. refers to the critical $p$-value. Panel B refers to Engle and Sheppard (2001) test, the null hypothesis Lambda being that there is a Constant Conditional Correlation (CCC). 
In Panel B of Table 4, we implement Engle and Sheppard (2001) test of constant versus dynamic conditional correlations (regarding step \#2 of the DCC). The test is based on the null hypothesis of constant correlations against an alternative of time-varying correlations:

$$
H_{0}: R_{t}=\bar{R} \forall t \in T
$$

The test statistic under the null hypothesis is asymptotically $\chi 2(\mathrm{~N}(\mathrm{~N}-1) / 2)$ and requires the fitting of a CCC-GARCH model first (Doan 2013). Test results show a statistically significant rejection of the constant conditional correlation (CCC) hypothesis for all pair-wise conditional correlations among the GCC countries. By rejecting the null of a constant correlation in favor of a dynamic structure, the estimated Multivariate GARCH model for the GCC countries and volatility indices can, therefore, be used for inference and drawing of economic implications and conclusions.

\section{Conclusions}

This study analyzes the conditional correlations between GCC stock market returns and the volatility in the oil market, gold market, and the international equity market. The originality of our work lies in the use of volatility indices (considered in log-difference) for the econometric investigation (under the form of conditional correlations between countries), departing from the canonical representation of stock returns.

By using weekly data, the estimated DCC-GARCH models reveal several significant findings. First, the GCC stock market returns are negatively correlated with each of the volatility measures, and the correlations are stronger during crisis periods. Second, the GCC stock returns are most correlated to oil shocks, followed by shocks in the global equity market, and are least correlated to gold shocks. This finding reveals the dependency of corporate cash flows of the GCC region on the crude oil market. At the same time, fluctuations in gold prices do not always affect the decision making of equity market participants in GCC markets. Lastly, among the six GCC countries, the stock markets of Saudi Arabia and Qatar are the most sensitive to all shocks. In contrast, Bahrain's stock market correlates weakly to shocks in the oil, gold, and the international equity market. This result could be due to the different degrees of economic diversification of each GCC country, or to their various exposures to the global equity market.

These results are essential to equity investors and fund managers alike. The negative correlations between the GCC stock markets and oil volatility suggest that investors should adjust their holdings when oil volatility is rising, especially during turmoil periods. The weak correlation between GCC stock markets and gold volatility suggests the potential role of gold in portfolio diversification. In light of our findings, the main practical implication for policymakers and banking analysts would be to focus on priority on the volatility originating from Saudi Arabia and the Qatar, which are the most sensitive countries in terms of volatility among the GCC countries.

Author Contributions: A.A.: Conceptualization, Methodology, Software, Estimation, Writing-Original draft preparation. J.C.: Data curation, Writing-Final draft preparation, Software, Estimation. All authors have read and agreed to the published version of the manuscript.

Funding: This research received no external funding.

Conflicts of Interest: The authors declare no conflict of interest. 


\section{Appendix A}

Table A1. VAR Lag Selection (up to ten lags).

\begin{tabular}{cccccc}
\hline Lag & Log-Likelihood & p(LR) & AIC & BIC & HQC \\
\hline 1 & $10,205.229$ & & -28.669 & $-28.398^{*}$ & $-28.564^{*}$ \\
\hline 2 & $10,245.906$ & 0.0001 & $-28.682^{*}$ & -28.180 & -28.488 \\
\hline 3 & $10,278.286$ & 0.002 & -28.672 & -27.938 & -28.388 \\
\hline 4 & $10,306.856$ & 0.013 & -28.651 & -27.685 & -28.278 \\
\hline 5 & $10,323.628$ & 0.585 & -28.597 & -27.399 & -28.134 \\
\hline 6 & $10,354.731$ & 0.004 & -28.583 & -27.154 & -28.031 \\
\hline 7 & $10,386.258$ & 0.003 & -28.570 & -26.909 & -27.928 \\
\hline 8 & $10,413.702$ & 0.022 & -28.546 & -26.653 & -27.815 \\
\hline 9 & $10,426.620$ & 0.894 & -28.481 & -26.357 & -27.660 \\
\hline 10 & $10,459.463$ & 0.001 & -28.472 & -26.116 & -27.562 \\
\hline
\end{tabular}

Note: * stands for the automated lag detected. This Table computes selection criteria for the order of the VAR(p), following the Box-Jenkins methodology. 
Table A2. Unit root tests for selected series.

\begin{tabular}{|c|c|c|c|c|c|c|c|c|c|c|c|c|}
\hline ADF Test & SaudiArabia & ld_SaudiArabia & Kuwait & ld_Kuwait & UAE & ld_UAE & Qatar & ld_Qatar & Bahrain & ld_Bahrain & Oman & ld_Oman \\
\hline \multicolumn{13}{|l|}{ Test with constant } \\
\hline Test Statistic: & -2.545 & -13.435 & -2.641 & -5.868 & -2.572 & -9.633 & -2.585 & -25.498 & -1.551 & -6.324 & -3.856 & -4.902 \\
\hline Asymptotic critical $p$ & 0.104 & 0.001 & 0.084 & 0.001 & 0.098 & 0.001 & 0.096 & 0.001 & 0.507 & 0.001 & 0.002 & 0.001 \\
\hline \multicolumn{13}{|l|}{ Test with constant and Trend } \\
\hline Test Statistic: & -2.831 & -13.437 & -3.505 & -5.872 & -2.635 & -9.630 & -2.512 & -25.495 & -2.437 & -6.316 & -3.877 & -5.380 \\
\hline $\begin{array}{c}\text { Asymptotic critical } p \text {. } \\
\text { KPSS }\end{array}$ & 0.185 & 0.001 & 0.038 & 0.001 & 0.2645 & 0.001 & 0.322 & 0.001 & 0.360 & 0.001 & 0.012 & 0.001 \\
\hline Truncation Delay Parameter & 6 & 6 & 6 & 6 & 6 & 6 & 6 & 6 & 6 & 6 & 6 & 6 \\
\hline Test Statistic: & 1.940 & 0.092 & 4.184 & 0.233 & 1.863 & 0.118 & 2.499 & 0.099 & 6.311 & 0.267 & 0.756 & 0.367 \\
\hline Critical $p$ & $<0.01$ & $>0.10$ & $<0.01$ & $>0.10$ & $<0.01$ & $>0.10$ & $<0.01$ & $>0.10$ & $<0.01$ & $>0.10$ & $<0.01$ & 0.091 \\
\hline
\end{tabular}

Note: For the sake of brevity, we only present the unit root tests for the first six GCC indices. The procedure is entirely redundant for all other variables included in the database. ADF stands for Augmented Dickey-Fuller: it is testing down from 19 lags, criterion AIC. 
Table A3. Full List of Data Source.

\begin{tabular}{|c|c|}
\hline GCC Countries: & $\begin{array}{c}\text { GCC Stock Data was retrieved from Bloomberg } \\
\text { https://www.bloomberg.com/professional/solution/bloomberg-terminal/ }\end{array}$ \\
\hline Brent: & $\begin{array}{c}\text { Data was retrieved from Bloomberg } \\
\text { https://www.bloomberg.com/professional/solution/bloomberg-terminal/ }\end{array}$ \\
\hline OPEC: & $\begin{array}{c}\text { Data was retrieved from Bloomberg } \\
\text { https://www.bloomberg.com/professional/solution/bloomberg-terminal/ }\end{array}$ \\
\hline STLSFI: & Link: https://fred.stlouisfed.org \\
\hline OVX & $\begin{array}{l}\text { http://www.cboe.com/products/vix-index-volatility/volatility-on-etfs/cboe-crude- } \\
\text { oil-etf-volatility-index-ovx }\end{array}$ \\
\hline Stock Market SMU & http://www.ub.edu/rfa/uncertainty-index/\#Reference \\
\hline VIX & http://www.cboe.com/vix \\
\hline GVZ & $\begin{array}{l}\text { Gold Price Uncertainty http://www.cboe.com/products/vix\$-\$index\$-\$volatility/ } \\
\text { volatility\$-\$on-\$etfs/cboe\$-\$gold\$-\$etf\$-\$volatility\$-\$index\$-\$gvz }\end{array}$ \\
\hline
\end{tabular}

\section{References}

Akoum, Ibrahim, Michael Graham, Jarno Kivihaho, Jussi Nikkinen, and Mohammed Omran. 2012. Co-movement of oil and stock prices in the GCC region: A wavelet analysis. Quarterly Review of Economics and Finance 52: 385-94. [CrossRef]

Alqahtani, Abdullah. 2019. Do Global Financial, Oil, and Gold Volatility Shocks Affect the GCC Stock Markets? Emerging Economy Studies 5: 157-75. [CrossRef]

Alqahtani, Abdullah, Tony Klein, and Ali Khalid. 2019. The impact of oil price uncertainty on GCC stock markets. Resources Policy 64: 101526. [CrossRef]

Alqahtani, Abdullah, Amine Lahiani, and Ali Salem. 2020. Crude oil and GCC stock markets: New evidence from GARCH co-integration and Granger causality approaches. International Journal of Energy Sector Management. [CrossRef]

Ardia, David. 2008. Bayesian estimation of the GARCH $(1,1)$ model with normal innovations. Financial Risk Management with Bayesian Estimation of GARCH Models. Theory and Applications 612: 17-37.

Arouri, Mohamed, and Christophe Rault. 2012. Oil prices and stock markets in GCC countries: Empirical evidence from panel analysis. International Journal of Finance \& Economics 17: 242-53.

Arouri, Mohamed, Amine Lahiani, and Duc Khuong Nguyen. 2011. Return and volatility transmission between world oil prices and stock markets of the GCC countries. Economic Modelling 28: 1815-25. [CrossRef]

Ausín, María Concepción, and Pedro Galeano. 2007. Bayesian estimation of the Gaussian mixture GARCH model. Computational Statistics \& Data Analysis 51: 2636-52.

Aziz, Omar Ghazy. 2018. Institutional quality and FDI inflows in Arab economies. Finance Research Letters 25: 111-23. [CrossRef]

Baba, Yoshihisa, Robert F. Engle, Dennis F. Kraft, and Kenneth F. Kroner. 1990. Multivariate Simultaneous Generalized $A R C H$. Working Paper. San Diego: Department of Economics, University of California.

Bilan, Yuriy, Stanislaw Gedek, and Grzegorz Mentel. 2018. The analysis of oil price and ruble exchange rate. Transformations in Business \& Economics 17: 195-205.

Bley, Jorg, and Mohsen Saad. 2019. An analysis of technical trading rules: The case of MENA markets. Finance Research Letters. [CrossRef]

Bollerslev, Tim, and Jeffrey M. Wooldridge. 1992. Quasi-maximum likelihood estimation and inference in dynamic models with time-varying covariances. Econometric Reviews 1: 143-73. [CrossRef]

Delcoure, Natalya, and Harmeet Singh. 2018. Oil and equity: Too deep into each other. Journal of Economics and Finance 42: 89-111. [CrossRef]

Dkhili, Hichem, and Lassad Dhiab. 2018. The Relationship between Economic Freedom and FDI versus Economic Growth: Evidence from the GCC Countries. Journal of Risk and Financial Management 11: 81. [CrossRef]

Doan, Tom. 2013. RATS Handbook for ARCH/GARCH and Volatility Models. Evanston: Estima WINRATS. 
Engle, Robert. 2002. Dynamic conditional correlation: A simple class of multivariate generalized autoregressive conditional heteroskedasticity models. Journal of Business and Economic Statistics 20: 339-50. [CrossRef]

Engle, Robert. 2009. Anticipating Correlations: A New Paradigm for Risk Management. Princeton: Princeton University Press.

Engle, Robert, and Kevin Sheppard. 2001. Theoretical and Empirical Properties of Dynamic Conditional Correlation Multivariate GARCH. Working Paper NBER (No. w8554). Cambridge: National Bureau of Economic Research.

Fayyad, Abdallah, and Kevin James Daly. 2011. The impact of oil price shocks on stock market returns: Comparing GCC countries with the UK and USA. Emerging Markets Review 12: 61-78. [CrossRef]

Guesmi, Khaled, and Salma Fattoum. 2014. The relationship between oil price and OECD stock markets: A multivariate approach. Economics Bulletin 34: 510-19.

Hammoudeh, Shawkat, and Kyongwook Choi. 2006. Behavior of GCC stock markets and impacts of US oil and financial markets. Research in International Business and Finance 20: 22-44. [CrossRef]

Hammoudeh, Shawkat, Tengdong Liu, Chia-Lin Chang, and Michael McAleer. 2013. Risk spillovers in oil-related CDS, stock, and credit markets. Energy Economics 36: 526-35. [CrossRef]

Khalfaoui, Rabeh, Mohamed Boutahar, and Heni Boubaker. 2015. Analyzing volatility spillovers and hedging between oil and stock markets: Evidence from wavelet analysis. Energy Economics 49: 540-49. [CrossRef]

Kumar, Surender, Shunsuke Managi, and Akimi Matsuda. 2012. Stock prices of clean energy firms, oil, and carbon markets: A vector autoregressive analysis. Energy Economics 34: 215-26. [CrossRef]

Loganathan, Nanthakumar, Dalia Štreimikienè, Tirta Nugraha Mursitama, Muhammad Shahbaz, and Abbas Mardani. 2018. How Real Oil Prices and Domestic Financial Instabilities are Good for GCC Countries Tourism Demand in Malaysia? Economics \& Sociology 11: 112-25.

Maghyereh, Aktham, and Ahmad Al-Kandari. 2007. Oil prices and stock markets in GCC countries: New evidence from nonlinear cointegration analysis. Managerial Finance 33: 449-60. [CrossRef]

Maghyereh, Aktham, Basel Awartani, and Panagiotis Tziogkidis. 2017. Volatility spillovers and cross-hedging between gold, oil, and equities: Evidence from the Gulf Cooperation Council countries. Energy Economics 68: 440-53. [CrossRef]

Malik, Farooq, and Shawkat Hammoudeh. 2007. Shock and volatility transmission in the oil, US, and Gulf equity markets. International Review of Economics and Finance 16: 357-68. [CrossRef]

Mensi, Walid, Makram Beljid, Adel Boubaker, and Shunsuke Managi. 2013. Correlations and volatility spillovers across commodity and stock markets: Linking energies, food, and gold. Economic Modelling 32: 15-22. [CrossRef]

Mensi, Walid, Shawkat Hammoudeh, and Aviral Kumar Tiwari. 2016. New evidence on hedges and safe havens for Gulf stock markets using the wavelet-based quantile. Emerging Markets Review 28: 155-83. [CrossRef]

Mohanty, Sunil K., Mohan Nandha, Abdullah Q. Turkistani, and Muhammed Y. Alaitani. 2011. Oil price movements and stock market returns: Evidence from Gulf Cooperation Council (GCC) countries. Global Finance Journal 22: 42-55. [CrossRef]

Muharam, Harjum, Wisnu Mawardi, Erman Denny Arfinto, and Najmudin Najmudin. 2019. Volatility spillovers under difference in the degree of market integration: Evidence from the selected Asian and Eastern European stock markets. Journal of International Studies 12: 134-50. [CrossRef]

Nasreen, Samia, Syed Asif Ali Naqvi, Aviral Kumar Tiwari, Shawkat Hammoudeh, and Syed Ale Raza Shah. 2020. Wavelet-Based Analysis of the Co-Movement between Sukuk Bonds and Shariah Stock Indices in the GCC Region: Implications for Risk Diversification. Journal of Risk and Financial Management 13: 63. [CrossRef]

Pandey, Vikas. 2018. Volatility spillover from crude oil and gold to BRICS equity markets. Journal of Economic Studies 45: 426-40. [CrossRef]

Sadorsky, Perry. 2012. Correlations and volatility spillovers between oil prices and the stock prices of clean energy and technology companies. Energy Economics 34: 248-55. [CrossRef]

Zarour, Bashar Abu. 2006. Wild oil prices, but brave stock markets! The case of GCC stock markets. Operational Research 6: 145-62. [CrossRef]

(C) 2020 by the authors. Licensee MDPI, Basel, Switzerland. This article is an open access article distributed under the terms and conditions of the Creative Commons Attribution (CC BY) license (http://creativecommons.org/licenses/by/4.0/). 